\title{
Impact of food advertising on food purchases by students in primary and secondary schools in south-eastern Poland
}

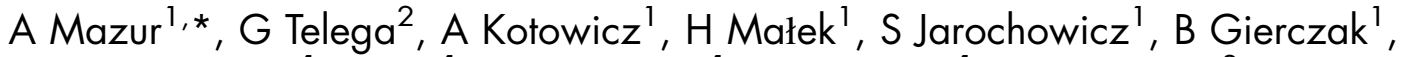 \\ M Mazurkiewicz ${ }^{1}$, T Pop $^{1}, K^{2}$ Zajkiewicz ${ }^{1}$, Mobrucki $^{1}$ and D Mazur ${ }^{3}$ \\ ${ }^{1}$ Institute of Physiotherapy, University of Rzeszow, St. Warszawska 26a, 35-205 Rzeszow, Poland: ${ }^{2}$ Department \\ of Pediatrics, Medical College of Wisconsin, Milwaukee, WI, USA: ${ }^{3}$ Faculty of Electrical and Computer \\ Engineering, Technical University of Rzeszow, Rzeszow, Poland
}

Submitted 13 July 2007: Accepted 20 January 2008: First published online 20 March 2008

\begin{abstract}
Aim: The aim of the present study was to determine the impact of food advertising in primary and secondary schools on the food purchasing habits of children. Methods: All forty-four primary and secondary schools in Rzeszow, Poland were included in the investigation; 15000 children attend primary and secondary schools in the region. Schools were visited by members of the research team, who filled in a questionnaire regarding the type of food products displayed or advertised in the school shop window and recorded the presence of direct corporate advertising in the proximity of the school shop. Shop owners were asked to fill in a form describing food purchases by students within the week preceding the visit. The school principal (or one of teachers) completed a form describing the school's policy regarding food advertising and the sponsorship of school activities by food companies.

Results: Recommended foods like milk, yoghurts and fruit were offered by only $40.9 \%$ of shops. There was a correlation between foods offered in the shop and foods purchased by students. In schools, 40.9\% (95\% CI 25.8, 56.0\%) of shop windows displayed or advertised 'healthy' foods while $9 \cdot 1 \%$ (95\% CI $0 \cdot 0,17 \cdot 9 \%$ ) of shops displayed advertisements of food companies. The difference between display of 'healthy' food in shop windows and display of food on company advertisements was significant (likelihood ratio $\chi^{2}$ test, $P<0 \cdot 04$ ). Type of school (primary $v$. secondary) was not significant factor in advertising or purchasing pattern.

Conclusions: Educational programmes should be introduced in schools with the aim of improving the understanding of nutritional principles among pupils, teachers and parents.
\end{abstract}

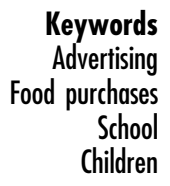

Keywords dvertising School Children
Nutrition is the main determinant of normal child development. Learning healthy nutritional habits is important for the prevention of obesity and its complications. School is a very important place for shaping eating habits in schoolchildren. Schools can implement an active policy in order to teach principles of nutrition and strengthen appropriate feeding behaviours. Many successful obesity prevention programmes have taken place in schools ${ }^{(1)}$.

The aim of the present study was to determine the impact of food advertising in primary and secondary schools on the food purchasing habits of children. No study to date has examined this subject in Poland.

\section{Methods}

Rzeszow is the largest town in south-east Poland, having a population of about 200000 . The population is pre- dominantly of Caucasian origin, without significant ethnic minorities. All forty-four primary and secondary schools in Rzeszow were included in the investigation; about 15000 children attend the examined schools. There were twenty-eight primary (8971 pupils) and sixteen secondary schools (5225 pupils) in the region. There were no socioeconomic differences among students of the viewed schools. The Ethical Committee of the Faculty of Medicine, University of Rzeszow approved the study.

Schools were visited by members of the research team during school hours. The typical school day starts at 08.00 hours and ends at 15.00 hours. The research group consisted of a paediatrician, a school pedagogue, a hygienist and students of the Physiotherapy Faculty of the University of Rzeszow. The presence and location of the school's food shop were recorded, as were the type of food products displayed or advertised in the shop window. We also recorded the presence of direct 
corporate advertising in the proximity of the shop and noted whether the school building, classrooms, corridors or gymnasium had food company advertisements. Shop owners were asked to fill in a form to record food purchases by students within the week preceding the visit. The school principal (or one of teachers) filled in a form describing the school's policy regarding food advertising and sponsorship of school activities by food companies.

We analysed whether 'healthy' foods were displayed or advertised in school shops. We defined as 'healthy' those foods recommended as staple foods in the recent release of the US Department of Agriculture's My Pyramid food guidance. Examples of such foods include fruit, milk, yoghurt, sandwiches and salads ${ }^{(2)}$. Our criteria required that the meal provide a balanced combination of protein, fats and carbohydrates without significant deficiencies in minerals and vitamins. For example, sandwiches in most of the shops contained bread, cold meat, butter or mayonnaise, and either tomatoes or salad. They are estimated to provide a nutritionally balanced meal containing protein, fats (mostly saturated) and carbohydrates.

Displays, advertisements and purchases were calculated as a percentage of all schools examined. The Statistical Package for the Social Sciences statistical software package (SPSS Inc., Chicago, IL, USA) was used to calculate means and confidence intervals. In each school each food group was classified into one of four categories: advertised and purchased; advertised and not purchased; not advertised and purchased; and not advertised and not purchased. The distribution based on this classification is displayed in Table 2. The $\chi^{2}$ test was used to analyse the relationship between food advertisements and purchases, by calculating how often specific advertised foods were actually purchased.

\section{Results}

There were no socio-economic differences among students of the viewed schools.

The current study revealed the ubiquitous presence of a school shop in all of the schools investigated. All school shops were selling food. The foods most often offered in school shops are shown in Table 1. 'Healthy' foods such as milk, yoghurt and fruit were offered by only $40.9 \%$ of shops. Thus, in nearly $60 \%$ of schools, children had no 'healthy' foods available at the school shop. The foods most often bought from the school shops by schoolchildren are shown in Table 1. Even in those shops where 'healthy' food was offered the sales of 'healthy' food items were low. Chips, chocolate bars and fresh cakes were in greatest demand in the majority of shops. There was a correlation between food offered in the shop and food purchased by the students. The display or
Table 1 Relationship between offered and purchased food products in school shops, Rzeszow, Poland

\begin{tabular}{lcc}
\hline & $\begin{array}{c}\text { Displayed or } \\
\text { advertised } \\
(\%)\end{array}$ & $\begin{array}{c}\text { Purchased } \\
(\%)\end{array}$ \\
\hline Crisps and popcorn & 82 & 70 \\
Chocolate bars & 91 & 89 \\
Fresh pastry & 55 & 82 \\
Fruit juices & 57 & 52 \\
Sodas & 43 & 61 \\
Other sweetened drinks & 57 & 64 \\
Water and seltzer water & 18 & 27 \\
Hard candies and lollipops & 82 & 64 \\
Jellybeans and soft candies & 23 & 11 \\
Chewing gum & 57 & 48 \\
Ice cream & 14 & 25 \\
Sandwiches & 11 & 7 \\
Coffee & 7 & 0 \\
Fruits & 34 & 5 \\
Cookies (fresh) & 11 & 7 \\
Cookies (packed) & 39 & 30 \\
Milk and yoghurts & 11 & 5 \\
Other dry snacks & 34 & 14 \\
Hot meals & 5 & 5 \\
Salads & 7 & 0 \\
\hline
\end{tabular}

Table 2 Relationship between advertised and purchased food products in school shops, Rzeszow, Poland

\begin{tabular}{lrc}
\hline & \multicolumn{2}{c}{ Specific food was advertised } \\
\cline { 2 - 3 } & No & Yes \\
\hline Advertised food was purchased & & \\
No & 463 & 125 \\
Yes & 95 & 197 \\
\hline
\end{tabular}

Correlation between food advertised in the shop and food purchased by the students was significant $(P<0.001)$.

advertisement of a specific food was strongly associated with purchase of that food (Table 2).

There were no statistically significant differences in the presence of 'healthy' foods in the shops of primary schools $v$. secondary schools. Prices of the products sold ranged from $0 \cdot 3$ to $2 €$. There were no statistically significant differences in the price of 'healthy' foods compared with other products available in both types of school analysed.

In schools, $40 \cdot 9 \%(95 \% \mathrm{CI}, 25 \cdot 8,56 \cdot 0 \%)$ of shop windows displayed or advertised 'healthy' foods while $9 \cdot 1 \%(95 \% \mathrm{CI} 0 \cdot 0,17 \cdot 9 \%)$ of stores displayed advertisements of food companies. None of the advertisements of the food companies displayed or advertised 'healthy' foods. The difference between display of 'healthy' foods in shop windows and display of foods on company advertisements was significant (likelihood ratio $\chi^{2}$ test, $P<0 \cdot 04)$. There was no difference in the impact of advertising in the proximity of the shop $v$. advertising in the school building on purchasing behaviour. In schools 
using sponsorship from food companies, 30.4\% (95\% CI, $10 \cdot 1,30 \cdot 8 \%$ ) of venues advertised healthy foods. Compared with schools not using corporate sponsorship, the difference was not significant. Type of school (primary $v$. secondary) was not a significant factor in advertising or purchasing pattern.

\section{Discussion}

Environmental and lifestyle changes have followed political and economic transformation in Poland. The traditional nutrition habits are being replaced by processed foods with high energy content. These recent changes in dietary habits are conducive to the development of obesity. Current school curricula lack health education and the promotion of healthy nutrition. This makes children more susceptible to food advertising ${ }^{(3)}$.

In a previous study we found that $71.4 \%$ of foods advertised on Polish television are high in fat and sugar, $14 \cdot 3 \%$ of these are soft drinks and only $14 \cdot 3 \%$ of advertised products can be called 'healthy' (reduced-sugar drinks, bio-yoghurts) ${ }^{(4)}$.

There are two-way relationships between purchasing habits and advertising. Advertising influences purchasing towards high-fat, high-carbohydrate items. On the other hand, pupils' preferences can influence the supply of items sold in school shops. From the shopkeeper's perspective, 'healthy' foods are less convenient and more perishable ${ }^{(5)}$. Soft drinks, crisps and snacks are associated by adolescents with pleasure, being with friends, independence, affordability and convenience ${ }^{(5,6)}$. In the perception of adolescents, eating 'healthy' foods is linked with family meals and being at home ${ }^{(6-8)}$ rather than being with friends or at school. If 'healthy' food is not available for purchase it is not convenient for adolescents to take it with them from home ${ }^{(9,10)}$. Recently, food marketing to youth in schools has become even more intense, persuasive and creative. There are many types of direct advertising in schools, such as displays of soft drinks, fast foods or snacks. Corporate logos can be displayed on athletic scoreboards, sponsorship banners in gyms and in advertisements in school newspapers and yearbooks. Advertisements are also present on free textbook covers and the screen savers of school computers ${ }^{(11,12)}$. Some schools are now selling food advertising space on their athletes' warm-up suits, as well as inside and outside school buses ${ }^{(13)}$.

Although food advertising in schools in Poland is not yet as intense as in USA, there is a trend towards greater acceptance of these practices in schools ${ }^{(13)}$. Struggling with financial constrains schools start to use the help of food companies to organize school celebrations and support after-hours programmes. Hence, it often can be a challenge for school principals to find a balance between income and providing healthy food choices. Without clearly stated goals school policies often result in neglecting the latter.

In analysis of our data some limitations must be considered. The study was carried out in primary and secondary schools in only one Polish region. The other limitation is related to the fact that part of the survey investigation was based on data provided by school principals and school shop owners. There was surprising agreement in data received from school principals and school shop owners. Yet, we could not verify data on food purchases from independent sources.

In order to influence the nutritional habits of schoolchildren it may be necessary to introduce laws which would determine the principles of food advertising in schools.

Educational programmes should be introduced in schools in order to improve the understanding of nutritional principles among pupils, teachers and parents.

\section{Acknowledgements}

All authors of the manuscript had no conflicts of interest or sources of funding. All authors contributed in preparation of the manuscript. We would like to acknowledge Professor Elisabeth Poskitt for professional revision of the manuscript.

\section{References}

1. Veugelers PJ \& Fitzgerald AL (2005) Effectiveness of school programs in preventing childhood obesity: a multilevel comparison. Am J Public Health 95, 432-435.

2. US Department of Agriculture (not dated) MyPyramid.gov http://www.mypyramid.gov/professionals/index.html (accessed February 2008).

3. Powell LM, Szczypka G \& Chaloupka FJ (2007) Adolescent exposure to food advertising on television. Am J Prev Med 33, 4 Suppl., S251-S256.

4. Mazur A, Matusik P, Caroli MA \& Malecka-Tendera E (2006) Nutritional quality of advertised food addressed to children. Int J Obes (Lond) 30, Suppl. 2, S15.

5. Neumark-Sztainer D, Story M, Perry C \& Casey MA (1999) Factors influencing food choices of adolescents: findings from focus group discussions with adolescents. J Am Diet Assoc 99, 929-937.

6. Chapman G \& Maclean J (1993) 'Junk food' and 'healthy food': meanings of food in adolescent women's culture. J Nutr Educ 25, 108-113.

7. French SA, Story M, Hannan P, Breitlow KK, Jeffery RW, Baxter JS \& Snyder MP (1999) Cognitive and demographic correlates of low-fat vending snack choices among adolescents and adults. J Am Diet Assoc 99, 471-475.

8. Wechsler H, Brener ND, Kuester S \& Miller C (2001) Food service and foods and beverages available at school: results from the School Health Policies and Programs Study 2000. J School Health 71, 313-324.

9. Story M, Neumark-Sztainer D \& French SA (2002) Individual and environmental influences on adolescent eating behaviors. J Am Diet Assoc 102, S40-S51. 
10. Vereecken C \& Vandegehuchte A (2003) Measurement of parental occupation: agreement between parents and their children. Arch Public Heath 61, 141-149.

11. Nestle M (2002) Food Politics: How the Food Industry Influences Nutrition and Health. Los Angeles, CA: University of California Press.
12. French SA, Story M \& Fulkerson JA (2002) School food policies and practices: a state-wide survey of secondary school principals. J Am Diet Assoc 102, 1785-1789.

13. US General Accounting Office (2000) Public Education: Commercial Activities in Schools. Report to Congressional Requesters. GAO/HEHS-00-156. Washington, DC: US General Accounting Office. 